\title{
Diffusion lung capacity for carbon monoxide correlates with HRCT findings in patients with diffuse parenchymal lung disease
}

\author{
Ezzelregal G. Hieba ${ }^{1 *}$, Eldiasty E. Shaimaa ${ }^{2}$, Sheha S. Dina ${ }^{3}$ and Ahmed O. Noha ${ }^{1}$
}

\begin{abstract}
Diffusion lung capacity for carbon monoxide correlates with HRCT findings in patients with diffuse parenchymal lung disease.

Background: Diffuse parenchymal lung diseases (DPLDs) affect the alveolar epithelium, pulmonary capillary endothelium, basement membrane, and perivascular and perilymphatic tissues. High-resolution computed tomography (HRCT) of the chest is the gold standard modality for diagnosing DPLD. Pulmonary function tests usually show a restrictive defect in spirometry. Single breath diffusion lung capacity for carbon monoxide (DLCO-SB) technique is used to assess the diffuse parenchymal lung diseases, as there is thickening of the alveolar membrane and diminished total lung capacity due to interstitial processes with severe decline in the transfer factor. The aim of this work was to correlate between Warrick's HRCT fibrosis score and DLCO-SB in DPLD and to assess the possibility of using DLCO as an only tool to follow up DPLD to avoid repeated radiation exposure of the patients in HRCT chest (decrease need for radiological follow-up) or vice versa.

Results: This work recruited 89 patients over a period of 10 months duration, $74.2 \%$ of them were females. The Warrick's score, ground-glass opacity, irregular pleural margin, subpleural cyst, honeycombing, and septal and subpleural lines were represented as $96.6 \%, 70.8 \%, 55.1 \%, 49.4 \%$, and $48.3 \%$ respectively in HRCT of DPLD. Warrick's score and its subscores (severity score, extent score, alveolitis score, and fibrosis score) were associated with a highly significant decrease in different pulmonary function indices (FVC, FEV', TLC, and DLCO) with $P$ value 0.001. A highly significant correlation between DLCO grades and total score grades was found with $P$ value 0.001 , and $86.8 \%$ of the patients with severe DLCO affection showed severe degree of total fibrosis score.

Conclusions: Both DLCO-SB and HRCT fibrosis scores were significantly correlated. Lifelong follow-up of function and structure of the lung in DPLD is needed by HRCT and DLCO. In an attempt to minimize repeated radiation exposure and reduce cost, we suggest DLCO to be used alone for longer follow-up periods rather than HRCT chest.
\end{abstract}

Keywords: Fibrosis score, DLCO, HRCT, DPLD

\footnotetext{
* Correspondence: drhebaezz111213@gmail.com

'Lectureres of Chest Diseases, Chest Department, Ain Shams University, Cairo,

Egypt

Full list of author information is available at the end of the article
}

() The Author(s). 2020 Open Access This article is licensed under a Creative Commons Attribution 4.0 International License, which permits use, sharing, adaptation, distribution and reproduction in any medium or format, as long as you give appropriate credit to the original author(s) and the source, provide a link to the Creative Commons licence, and indicate if changes were made. The images or other third party material in this article are included in the article's Creative Commons licence, unless indicated otherwise in a credit line to the material. If material is not included in the article's Creative Commons licence and your intended use is not permitted by statutory regulation or exceeds the permitted use, you will need to obtain permission directly from the copyright holder. To view a copy of this licence, visit http://creativecommons.org/licenses/by/4.0/. 


\section{Background}

Diffuse parenchymal lung diseases (DPLDs) affect the alveolar epithelium, pulmonary capillary endothelium, basement membrane, and perivascular and perilymphatic tissues. Compromising a heterogeneous group of diseases, it occurs when an abnormal healing response was induced by injury to the lungs $[1,2]$.

Investigations are aiming to reach the etiology of DPLD. The most important part of the workup of patients with DPLD is a detailed and proper history taking to identify the possible etiology including occupational or drug exposures, for signs of conditions like connective tissue and autoimmune diseases, sarcoidosis, and infection [3].

HRCT of the chest is the gold standard modality for diagnosis of DPLD. It provides 10 times more resolution than the conventional, as it reveals details that cannot otherwise be visualized [4]. The most common CT patterns of fibrotic interstitial lung disease (ILD) are ground-glass opacities, reticulations, traction bronchiectasis, and honeycombing. Those patterns have specific and broadly agreed definitions [5].

Pulmonary function tests usually show a restrictive defect in spirometry. DLCO-SB technique is used to assess the DPLD, as there is a thickening of the alveolar membrane and a diminished total lung capacity (TLC) due to interstitial processes [6].

Semi-quantitative scoring methods help to provide a more precise assessment of quantity and type of ILD abnormalities in HRCT chest. Using semi-quantitative scoring systems on HRCT has been shown consistently to be significantly and inversely correlated with forced vital capacity (FVC \%), TLC, and DLCO predicted [7, 8]. One scoring system that has been used in several studies was developed and published by Warrick et al. [7].

In terms of assessing disease progression, it was found that patients with more severe fibrosis at baseline (or higher fibrosis scores) had a greater mean of decline in FVC and DLCO compared to groups with no or moderate fibrosis [9].

A clinico-radiological physiological scoring system is used to follow up patients with interstitial pulmonary fibrosis [10]. However, intending to reduce the frequency of performing HRCT during follow-up of patients with DPLD, we aimed to correlate between Warrick's HRCT fibrosis score and DLCO-SB in DPLD, to assess the possibility of using DLCO alone as a tool for follow-up of DPLD patients to minimize the radiation exposure of the patients in HRCT chest (decrease need for radiological follow-up) or vice versa.

\section{Methods}

This prospective cross-sectional study recruited $89 \mathrm{pa}$ tients having DPLD attending the Outpatient Clinics and Inpatient Departments of Pulmonology, Immunology, and Rheumatology at Ain Shams University Hospitals in the period from June 2019 to March 2020 as shown in Fig. 1.

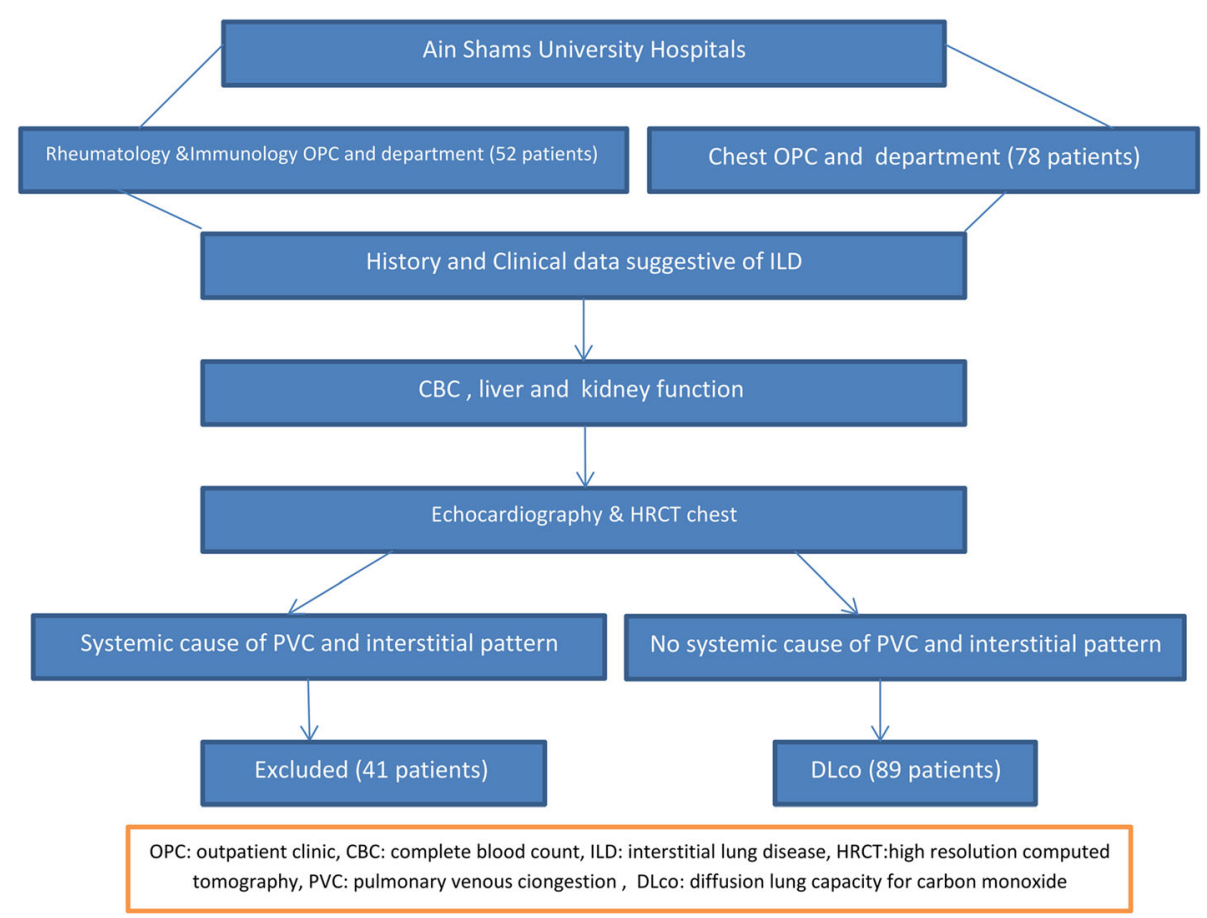

Fig. 1 Flow chart for patient selection 


\section{Inclusion criteria}

Patients older than 18 years old with DPLD either newly or previously diagnosed clinically dry dyspnea, dry cough and any other symptoms related to the etiology, and radiologically by HRCT Chest with different patterns without any of the exclusion criteria.

\section{Exclusion criteria}

Exclusion criteria were patients with comorbid cardiac, renal, or hepatic affection that may cause pulmonary venous congestion, patients with pulmonary or extrapulmonary malignancy, patients receiving radiotherapy and/ or chemotherapy and/or biological therapy, patients with vanishing lung syndrome, and those refusing to participate in the study.

A written informed consent was taken from all patients prior to enrollment, and all patients were subjected to the following:

1- History taking for occupational, environmental exposures, autoimmune diseases, family history, and any relevant pulmonary or systemic symptoms.

2- Laboratory investigations: $\mathrm{CBC}$, liver, kidney function, and collagen markers if not with the patient.

3- Echocardiography: To exclude heart as a cause of interstitial affection.

4- Spirometry and DLCO-SB: Performed according to the standard practice previously discussed in details $[11,12]$ using Viasys Healthcare Diffusion with built-in spirometer, D-97204 Hochberg, Germany. The spirometry indices recorded were forced expiratory volume in first second $\left(F E V_{1}\right)$, forced vital capacity $(F V C)$, and $F E V_{1} / F V C$ ratio. Also, DLCO$S B \%$ (best/predicted) was recorded after correction with the patient hemoglobin. By an online calculator available at https://www.uptodate.com/contents/ calculator-diffusing-capacity-for-carbon-monoxidedlco-correction-of-predicted-value-for-anemia-conventional-units.

5- HRCT chest: The study was done in the CT unit at Ain Shams University Hospitals by General Electric Bright Speed Elite 16 slices CT device, USA. Ethical approval was obtained to use the data stored on (PACS) picture archiving and communication system.

\section{Method of HRCT examination}

Thin sections were acquired with an interval of $1-2 \mathrm{~cm}$ between the two sets of images and were considered sufficient to detect abnormalities in diffuse lung diseases.

Fundamental technical protocols are as follows:

- Slice thickness: $0.625-1.25 \mathrm{~mm}$
- Scan time: $0.5-1 \mathrm{~s}$

- kV: 120

- mAs: $100-200$

- Collimation: $1.5-3 \mathrm{~mm}$

- Matrix size: $768 \times 768$ or the largest available

- FOV: $35 \mathrm{~cm}$

- Reconstruction algorithm: high spatial frequency

- Window: lung window (window level, $-700 \mathrm{HU}$; window width, $1500 \mathrm{HU}$ )

- Patient position: supine (routinely), from lung apices to the bases.

- Level of inspiration: full inspiration (routinely recommended).

Estimation of the total Warrick's score 30 points maximum with extent score and severity score as previously described by Warrick et al. [7] (Table 1).

Total score was expressed as follows:

a. Normal: zero point "no normal cases were involved in this work"

b. Mild: less than 8 points

c. Moderate: from 8 to 15 points.

d. Severe: more than 15 points.

Also, two more scores were added

a. Alveolitis score (ground-glass opacity (GGO) plus its severity score)

b. Fibrosis score (CT abnormalities other than GGOsplus its severity score)

\section{Ethical consideration}

The study was approved by the Ethical Committee Board of Ain Shams University and was carried out in accordance with the Declaration of Helsinki.

\section{Statistical data analysis}

Data was analyzed using computer program SPSS (Statistical Package for the Social Science; SPSS Inc., Chicago, IL, USA) release 15 for Microsoft Window (2006). Qualitative variables were presented as percentage and quantitative variables were presented as mean \pm SD. Student's $t$ test and Pearson's correlation coefficient were used as the test of significance; $P$ value less than 0.05 was considered as significant.

\section{Results}

This was a prospective study that recruited 89 patients presenting with DPLD, $74.2 \%$ of them were females; their mean age was $49.98 \pm 12.56$ years, range from 23 to 75 years old. Nine percent of the patients were farmers, and $15.7 \%$ were smokers. DPLD of unknown cause was found in $24.7 \%$ of patients (Tables 2) 
Table 1 Warrick's total score and its subscores

\begin{tabular}{llll}
\hline Severity score & & Extent score \\
\cline { 2 - 2 } Abnormality & Grading & & Number of each pulmonary segment involved \\
\hline Ground glass & 1 & 1 to 3 segments & Grading \\
Irregular pleural margin & 2 & 4 to 9 segments & 2 \\
Septal or subpleural lines & 3 & $>9$ segments \\
Honeycombing & 4 & N.B: extent of the disease measured for each abnormality \\
Subpleural cyst & 5 & \\
Maximal score & 15 & Maximal score \\
\hline Quoted from Warrick J et al. 1991 [7] & &
\end{tabular}

spiorometric and DLCO Parameters of the studied population were shown (Table 3 ).

As regards Warrick's score, the total score mean \pm SD was $17.38 \pm 5.90$ ranging from 7 to 29 . Alveolitis score and fibrosis score were $2.99 \pm 1.07$ and $14.40 \pm 5.32$ respectively. Severity score and extent score were $8.63 \pm$ 3.75 and $8.63 \pm 3.08$ respectively. GGO, irregular pleural margin, subpleural cyst, honeycombing, and septal and

Table 2 Demographics and associated risk factors or etiology of ILD among the studied population

\begin{tabular}{ll}
\hline & Total no. = 89 \\
\hline Age & \\
Mean \pm SD & $49.98 \pm 12.56$ \\
Range & $23-75$ \\
Sex & \\
Female & $66(74.2 \%)$ \\
Male & $23(25.8 \%)$ \\
Comorbidities & \\
DM & $31.5 \%$ \\
HTN & $43.8 \%$ \\
Hypothyroid & $4.5 \%$ \\
Associated risk factor or etiology & \\
Idiopathic & $22(24.7 \%)$ \\
Smoking & $14(15.7 \%)$ \\
Scleroderma & $6(6.7 \%)$ \\
Methotrexate & $3(3.4 \%)$ \\
Bird breeder & $9(10.1 \%)$ \\
Rheumatoid arthritis & $16(17.9 \%)$ \\
Systemic lupus & $5(5.6 \%)$ \\
Farmer & $8(9.0 \%)$ \\
Asbestos & $5(5.6 \%)$ \\
Sarcoidosis & $1(1.1 \%)$ \\
Pegagen markers & \\
\hline DMitive & $60(67.4 \%)$ \\
dilla & $29(32.6 \%)$ \\
\hline
\end{tabular}

DM diabetes mellitus, HTN hypertension subpleural lines were found in $96.6 \%, 70.8 \%, 55.1 \%$, $49.4 \%, 48.3 \%$ of the patients respectively (Table 4 ).

Warrick's score and its subscores (severity score, extent score, alveolitis score, and fibrosis score) were associated with a highly significant decrease in different pulmonary function indices (FVC, FEV1, TLC, and DLCO-SB). No significant correlation was found between FEV1/FVC ratio and Warrick's scores (Table 5).

The current study showed a significant decrease in FVC in patients with honeycombing in HRCT compared to patients without honeycombing $(59.33 \pm 19.59$ versus $68.51 \pm 21.01)$ with $P$ value 0.036 . Also, a highly significant decrease in FVC was noted in patients with subpleural cyst than those without $(57.4 \pm 21.78$ versus $72.02 \pm 16.27$ ) with $P$ value 0.001 (Table 6). A highly significant decrease in FEV1 was noticed in patients with

Table 3 Spirometry and diffusion parameters among the studied population

\begin{tabular}{ll}
\hline Spirometry and DLCO-SB & Total no. $\mathbf{8} \mathbf{9 9}$ \\
\hline FVC & \\
Mean \pm SD & $63.97 \pm 20.73$ \\
Range & $24.7-112$ \\
FEV $_{\mathbf{1}}$ & \\
$\quad$ Mean \pm SD & $61.93 \pm 16.97$ \\
Range & $26.8-98$ \\
FEV $\mathbf{1} /$ FVC & \\
Mean \pm SD & $79.32 \pm 6.17$ \\
Range & $56-88$ \\
TLC & \\
Mean \pm SD & $66.91 \pm 13.54$ \\
Range & $42.8-98$ \\
DLCO-SB \% & \\
Mean \pm SD & $44.13 \pm 18.50$ \\
Range & $11.8-79$ \\
\hline
\end{tabular}

$F V C$ forced vital capacity, $F E V$, forced expiratory volume in the first second, $T L C$ total lung capacity, DLCO-SB diffusion lung capacity for carbon monoxide single breath 
Table 4 Warrick's score and its characteristics among the studied population

\begin{tabular}{|c|c|}
\hline Characteristics of Warrick's score & Total no. $=89$ \\
\hline \multicolumn{2}{|l|}{$\overline{\mathrm{GGO}}$} \\
\hline Absent & $3(3.4 \%)$ \\
\hline Present & $86(96.6 \%)$ \\
\hline \multicolumn{2}{|l|}{ Irregular pleural margin } \\
\hline Absent & $26(29.2 \%)$ \\
\hline Present & $63(70.8 \%)$ \\
\hline \multicolumn{2}{|l|}{ Septal, subpleural lines } \\
\hline Absent & $46(51.7 \%)$ \\
\hline Present & $43(48.3 \%)$ \\
\hline \multicolumn{2}{|l|}{ Honeycombing } \\
\hline Absent & $45(50.6 \%)$ \\
\hline Present & $44(49.4 \%)$ \\
\hline \multicolumn{2}{|l|}{ Subpleural cyst } \\
\hline Absent & $40(44.9 \%)$ \\
\hline Present & 49 (55.1\%) \\
\hline \multicolumn{2}{|l|}{ Severity score } \\
\hline Mean \pm SD & $8.63 \pm 3.75$ \\
\hline Range & $1-15$ \\
\hline \multicolumn{2}{|l|}{ Warrick extent score } \\
\hline Mean \pm SD & $8.63 \pm 3.08$ \\
\hline Range & $3-15$ \\
\hline \multicolumn{2}{|l|}{ Alveolitis score } \\
\hline Mean \pm SD & $2.99 \pm 1.07$ \\
\hline Range & $0-4$ \\
\hline \multicolumn{2}{|l|}{ Fibrosis score } \\
\hline Mean \pm SD & $14.40 \pm 5.32$ \\
\hline Range & $4-25$ \\
\hline \multicolumn{2}{|l|}{ Total score } \\
\hline Mean \pm SD & $17.38 \pm 5.90$ \\
\hline Range & $7-29$ \\
\hline
\end{tabular}

GGO ground-glass opacity
Table 6 Correlation between forced vital capacity and Warrick's score indices

\begin{tabular}{llllll}
\hline & FVC & & $\begin{array}{l}\text { Test } \\
\text { value }\end{array}$ & $\begin{array}{l}\boldsymbol{P} \\
\text { value }\end{array}$ & Sig. \\
\cline { 2 - 3 } & Mean \pm SD & Range & & & \\
GGO & & & & & \\
Absent & $77.33 \pm 3.79$ & $73-80$ & $138^{\mathrm{a}}$ & 0.258 & NS \\
Present & $63.51 \pm 20.92$ & $24.7-112$ & & &
\end{tabular}

Irregular pleural margin

$\begin{array}{llllll}\text { Absent } & 69.15 \pm 22.84 & 24.7-112 & 1.525^{\mathrm{a}} & 0.131 & \text { NS } \\ \text { Present } & 61.84 \pm 19.58 & 26-100 & & & \end{array}$

Septal, subpleural lines

$\begin{array}{llllll}\text { Absent } & 68 \pm 21.7 & 26-100 & 1.926^{\mathrm{a}} & 0.057 & \text { NS } \\ \text { Present } & 59.66 \pm 18.94 & 24.7-112 & & & \end{array}$

\section{Honeycombing}

$\begin{array}{llllll}\text { Absent } & 68.51 \pm 21.01 & 26-112 & 2.131^{\mathrm{a}} & 0.036 & \mathrm{~S} \\ \text { Present } & 59.33 \pm 19.59 & 24.7-100 & & \end{array}$

\section{Subpleural cyst}

$\begin{array}{llllll}\text { Absent } & 72.02 \pm 16.27 & 34.4-100 & 3.517^{\mathrm{a}} & 0.001 & \text { HS }\end{array}$

Present $\quad 57.4 \pm 21.78 \quad 24.7-112$

GGO ground glass opacity, FVC forced vital capacity, $P$ value $>0.05$ : nonsignificant; $P$ value $<0.05$ : significant; $P$ value $<0.01$ : highly significant Independent $t$ test

subpleural cyst than those without $(55.69 \pm 15.9$ versus $69.57 \pm 15.16$ (with $P$ value 0.001 (Table 7).

This study showed a highly significant correlation between different DLCO-SB degrees of affection and total Warrick's score degrees with $P$ value 0.001 . Most patients (86.8\% from 38 patients) with severe degree of diffusion defect showed severe degree of total Warrick's score (Table 8).

Patients with GGO in HRCT showed a significant decrease in DLCO-SB than patients without GGO in HRCT chest $(43.3 \pm 18.17$ versus $68 \pm 12.12)$ with $P$ value 0.022 . Also, a highly significant decrease in DLCO-SB was noted in patients with subpleural cyst and honeycombing with $P$ value 0.001 and 0.002 respectively (Table 9).

The validity of DLCO-SB for the prediction of GGO was assessed, and the area under the receiver operating

Table 5 Correlation between Warrick's score and different pulmonary function indices among the studied population

\begin{tabular}{|c|c|c|c|c|c|c|c|c|c|c|}
\hline & \multicolumn{2}{|l|}{ FVC } & \multicolumn{2}{|l|}{$\mathrm{FEV}_{1}$} & \multicolumn{2}{|c|}{$\mathrm{FEV}_{1} / \mathrm{FVC}$} & \multicolumn{2}{|l|}{ TLC } & \multicolumn{2}{|c|}{ DLCO-SB\% } \\
\hline & $R$ & $P$ value & $R$ & $P$ value & $R$ & $P$ value & $R$ & $P$ value & $R$ & $P$ value \\
\hline Severity score & -0.471 & 0.001 & -0.460 & 0.001 & -0.009 & 0.932 & -0.391 & 0.001 & -0.575 & 0.001 \\
\hline Extent score & -0.502 & 0.001 & -0.524 & 0.001 & -0.050 & 0.644 & -0.451 & 0.001 & -0.619 & 0.001 \\
\hline Alveolitis score & -0.632 & 0.001 & -0.555 & 0.001 & -0.037 & 0.728 & -0.639 & 0.001 & -0.890 & 0.001 \\
\hline Fibrosis score & -0.532 & 0.001 & -0.538 & 0.001 & -0.025 & 0.819 & -0.428 & 0.001 & -0.618 & 0.001 \\
\hline Total score & -0.581 & 0.001 & -0.570 & 0.001 & -0.022 & 0.836 & -0.496 & 0.001 & -0.713 & 0.001 \\
\hline
\end{tabular}

FVC forced vital capacity, FEV 1 forced expiratory volume in the first second, TLC total lung capacity, DLCO-SB diffusion lung capacity for carbon monoxide single breath 
Table 7 Correlation between forced expiratory volume in the first second and Warrick's score indices

\begin{tabular}{llllll}
\hline HRCT & FEV $_{1}$ & & Test & $P$ & Sig. \\
findings & value & value & \\
\cline { 2 - 3 } & Mean \pm SD & Range & & & \\
\hline
\end{tabular}

\begin{tabular}{cccccc}
\hline GGO & & & & & \\
Absent & $73.67 \pm 2.52$ & $71-76$ & $1.222^{\mathrm{a}}$ & 0.225 & NS \\
Present & $61.52 \pm 17.11$ & $26.8-98$ & & &
\end{tabular}

Irregular pleural margin

$\begin{array}{llllll}\text { Absent } & 65.26 \pm 17.83 & 30-98 & 1.193^{\mathrm{a}} & 0.236 & \text { NS } \\ \text { Present } & 60.55 \pm 16.55 & 26.8-91.9 & & & \end{array}$

Septal, subpleural lines

$\begin{array}{llllll}\text { Absent } & 64.15 \pm 18.37 & 26.8-98 & 1.283^{\mathrm{a}} & 0.203 & \text { NS } \\ \text { Present } & 59.55 \pm 15.17 & 34-89 & & & \end{array}$

\section{Honeycombing}

$\begin{array}{llllll}\text { Absent } & 64.74 \pm 16.45 & 26.8-89 & 1.594^{\mathrm{a}} & 0.115 & \text { NS } \\ \text { Present } & 59.05 \pm 17.2 & 30-98 & & & \end{array}$

\section{Subpleural cyst}

\begin{tabular}{llllll} 
Absent & $69.57 \pm 15.16$ & $34-98$ & $4.184^{\mathrm{a}}$ & 0.001 & HS \\
Present & $55.69 \pm 15.9$ & $26.8-88$ & & & \\
\hline
\end{tabular}

GGO ground glass opacity, $F E V_{1}$ forced expiratory volume in the first second, $P$ value $>0.05$ : non-significant; $P$ value $<0.05$ : significant; $P$ value $<0.01$ :

highly significant

${ }^{\text {a }}$ Independent $t$ test

characteristic (ROC) curve was 0.870 . A value of $\leq 54.2$ diffusion defect was statistically proposed as a cutoff value to predict presence of GGO (Fig. 2). Also, regarding the validity of DLCO-SB for the prediction of honeycombing in HRCT chest, the area under ROC curve was 0.685 . A value of $\leq 43$ diffusion defects was statistically proposed as a cutoff value to predict the presence of honeycombing (Fig. 3).

\section{Discussion}

HRCT of the chest is the gold standard modality for the diagnosis of DPLD [4]. The most common CT patterns of fibrotic ILD are GGO, reticulations, tractions bronchiectasis, and honeycombing [5]. Pulmonary function tests

Table 8 Correlation between degree of diffusion lung capacity for carbon monoxide and degree of total Warrick's score

\begin{tabular}{|c|c|c|c|c|c|c|}
\hline & \multicolumn{3}{|l|}{ DLCO-SB } & \multirow{3}{*}{$\begin{array}{l}\text { Test } \\
\text { value }\end{array}$} & \multirow{3}{*}{$\begin{array}{l}P \\
\text { value }\end{array}$} & \multirow[t]{3}{*}{ Sig. } \\
\hline & Mild & Moderate & Severe & & & \\
\hline & No. $=24$ & No. $=27$ & No. $=38$ & & & \\
\hline \multicolumn{7}{|c|}{ Warrick's total score } \\
\hline Mild & $1(4.2 \%)$ & $1(3.7 \%)$ & $0(0.0 \%)$ & 30.343 & 0.001 & $\mathrm{HS}$ \\
\hline Moderate & $19(79.2 \%)$ & $12(44.4 \%)$ & $5(13.2 \%)$ & & & \\
\hline Severe & $4(16.7 \%)$ & 14 (51.9\%) & 33 (86.8\%) & & & \\
\hline
\end{tabular}

Table 9 Correlation between DLCO-SB and Warrick's score indices

\begin{tabular}{|c|c|c|c|c|c|}
\hline \multirow{2}{*}{$\begin{array}{l}\text { HRCT } \\
\text { findings }\end{array}$} & \multicolumn{2}{|l|}{ DLCO-SB } & \multirow{2}{*}{$\begin{array}{l}\text { Test } \\
\text { value }\end{array}$} & \multirow{2}{*}{$\begin{array}{l}P \\
\text { value }\end{array}$} & \multirow[t]{2}{*}{ Sig. } \\
\hline & Mean \pm SD & Range & & & \\
\hline \multicolumn{6}{|l|}{ GGO } \\
\hline Absent & $68 \pm 12.12$ & $55-79$ & $2.330^{a}$ & 0.022 & $S$ \\
\hline Present & $43.3 \pm 18.17$ & $11.8-76$ & & & \\
\hline \multicolumn{6}{|c|}{ Irregular pleural margin } \\
\hline Absent & $49.15 \pm 18.49$ & $12-79$ & $1.659^{a}$ & 0.101 & NS \\
\hline Present & $42.06 \pm 18.25$ & $11.8-76$ & & & \\
\hline
\end{tabular}

Septal, subpleural lines

\begin{tabular}{|c|c|c|c|c|c|}
\hline Absent & $47.4 \pm 18.57$ & $11.8-76$ & $1.741^{\mathrm{a}}$ & 0.085 & NS \\
\hline Present & $40.64 \pm 17.99$ & $12-79$ & & & \\
\hline \multicolumn{5}{|c|}{ Honeycombing } & \\
\hline Absent & $50.12 \pm 17.11$ & $11.8-79$ & $3.253^{\mathrm{a}}$ & 0.002 & HS \\
\hline Present & $38.01 \pm 18.03$ & $12-70$ & & & \\
\hline \multicolumn{5}{|c|}{ Subpleural cyst } & \\
\hline Absent & $52.73 \pm 13.82$ & $23-76$ & $4.345^{\mathrm{a}}$ & 0.001 & HS \\
\hline Present & $37.11 \pm 18.99$ & $11.8-79$ & & & \\
\hline
\end{tabular}

$D L C O-S B$ diffusion lung capacity for carbon monoxide single breath, GGO ground-glass opacity, $P$ value $>0.05$ : non-significant; $P$ value $<0.05$ : significant; $P$ value $<0.01$ : highly significant andependent $t$ test

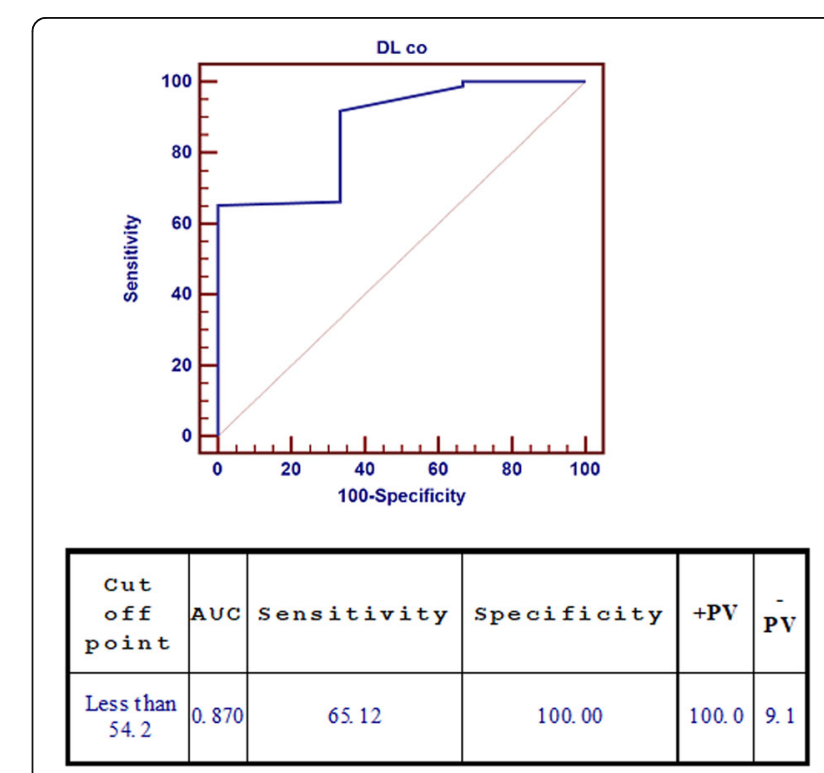

Fig. 2 ROC curve and coordinates for the best cutoff DLCO-SB value to predict ground-glass opacity. $\mathrm{ROC}$, receiver operating characteristic; AUC, area under the curve 


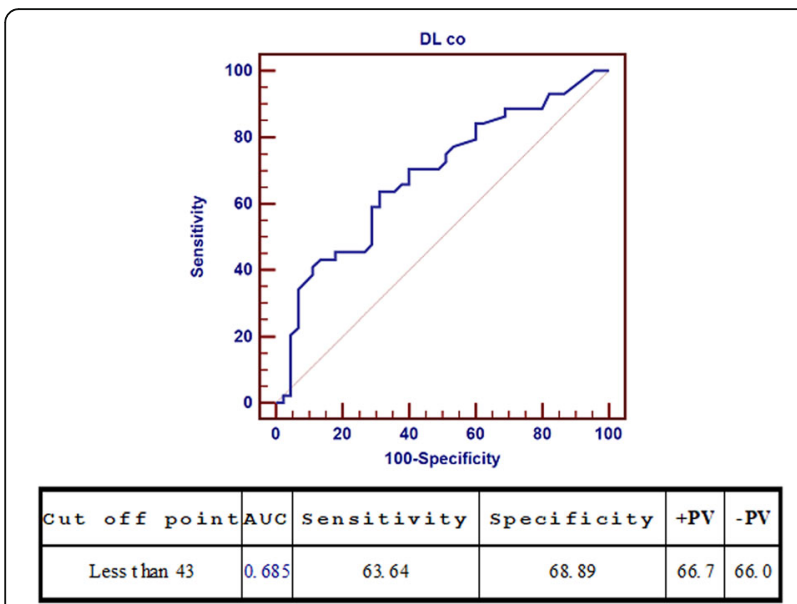

Fig. 3 ROC curve and coordinates for the best cutoff DLCO-SB value to predict honeycombing. ROC, receiver operating characteristic; $A \cup C$, area under the curve

usually show a restrictive defect in spirometry. As there is thickening of the alveolar membrane, DLCO-SB is also diminished [6].

This study aimed to evaluate the extent of DPLD using a semi-quantitative Warrick's HRCT score to determine the disease severity and its possible correlation with PFT including spirometry and DLCO-SB. They have been the only parameters considered to date to follow up cases with DPLD aiming to replace one of them by the other either to decrease cost or decrease radiation exposure.

This prospective study recruited 89 patients diagnosed with DPLD, $74.2 \%$ of them were females; their mean age was $49.98 \pm 12.56$ years. The age group was matched with the results of Abou Youssuf $\mathrm{H}$. et al.; however, the official ATS/ERS/JRS/ALAT guidelines 2011 stated that IPF occurs in the sixth and seventh decades [13, 14]. The higher incidence of DPLD in the female population in the studied group was consistent with Abou Youssuf et al. and Rifaat et al. who found out that the majority of the studied population were females [13, 15]. Additionally, it was in agreement with Hassan who studied the comparison of FVC, FVC/DLCO, and TLC/DLCO as an indicator for interstitial lung disease in patients with scleroderma [16].

DPLD was idiopathic in $24.7 \%$ of the cases. The observations of Kundu $\mathrm{S}$ et al. were similar; they concluded that unknown etiology was the most common cause of DPLD representing 38.04\% [17]. This was in contrast with A Kheliouen. et al. who found that sarcoidosis was the most common disease, followed by ILD associated with connective tissue diseases. The discrepancy might be due to lack of open lung biopsy in the study population [18].

DPLD as one of the restrictive lung diseases affecting the alveolar-capillary membrane is associated with lower
FVC\% and DLCO-SB especially in severe degrees as shown by this work and others [13, 19]. A recent study was not totally in agreement with this work results in this issue, which might be related to the difference in the number of patients recruited and the variability in the characteristics of the studied populations [20].

$\mathrm{FEV}_{1}, \mathrm{FEV}_{1} / \mathrm{FVC}$, and the TLC changes were consistent with Riad $\mathrm{N}$ et al. during their assessment of ILD with DLCO-SB and spirometry [21].

In the current study, Warrick's score and its subscores (severity score, extent score, alveolitis score, and fibrosis score) were associated with a highly significant decrease in different pulmonary function indices $\left(\mathrm{FVC}, \mathrm{FEV}_{1}, \mathrm{TLC}\right.$, and DLCO-SB). Previous studies showed the same results considering fibrosis score as interstitial score [22, 23].

Similar to the previous published data [24-27], we demonstrated that Warrick's semi-quantitative score was able to determine the severity of DPLD correlated well with FVC, TLC, and DLCO.

In other words, the current study aimed to investigate the comparative value of DLCO-SB and HRCT in diagnosing DPLD, and showed a highly significant correlation between different DLCO-SB degrees of diffusion defects and total Warrick's score degrees. These findings are consistent with Khanna et al. who found that most of the patients with severe fibrosis in HRCT were with severe diffusion defect [9].

Decline in spirometric indices and DLCO-SB were associated significantly with the different radiological patterns of CT chest. FVC was significantly decreased in patients with honeycombing and subpleural cyst in HRCT. Highly significant decrease in $\mathrm{FEV}_{1}$ was noted in patients with subpleural cyst. Also, this work demonstrated a highly significant decrease in DLCO-SB in patients with subpleural cyst and honeycombing and a significant decrease in DLCO-SB in patients with GGO.

These data are in accordance with Hussein et al. who found that FVC and DLCO-SB were significantly lower in fibrotic DPLD [28]. Also, Araki et al. who studied the effect of pulmonary cysts on DLCO-SB supported this work result [29]. Many other related studies went hand in hand with the current study results [30-32].

These significant correlations encouraged us to determine the cutoff values between DLCO-SB and the two extremes of HRCT structural changes of the lung, GGO, and honeycombing, to predict the value of DLCO-SB associated with these changes. A value of $\leq 54.2$ diffusion defect was statistically proposed as a cutoff value to predict the presence of ground-glass opacity "alveolitis score" with better area under the ROC curve 0.870. Also, the validity of DLCO-SB for prediction of honeycombing in HRCT chest was assessed, the area under ROC curve was 0.685 . A value of $\leq 43$ diffusion defect was statistically proposed as a cutoff value to predict presence of 
honeycombing. So first baseline HRCT in patients with DPLD to determine the pattern and extent of radiological affection could be enough then follow up with DLCO-SB and less frequently with HRCT to limit radiation exposure and decrease the cost.

This study had some limitations; the small number of studied population and the shorter duration of the work with no follow-up data. HRCT other scores may be needed to correlate with the functional assessment of the lung on a larger number of patients. Longer followup periods are recommended to validate this study's results and estimate the percentage of change of DLCO$\mathrm{SB}$ with each HRCT radiological pattern and with each type of ILD.

\section{Conclusion}

Structural changes in the lung can be detected by HRCT chest, and functional changes can be assessed by spirometry and more precisely by DLCO-SB; in this work, both were significantly correlated. Since DPLD patients need lifelong follow-up, assessment of function and structure of the lung by HRCT chest and DLCO-SB at the first visit, with subsequent follow-up of lung function mainly by DLCO-SB to decrease follow-up times with HRCT appeared to be satisfactory with less cost and minimizing repeated radiation exposure.

\section{Abbreviations \\ FVC: Forced vital capacity; $\mathrm{FEV}_{1}$ : Forced expiratory volume in the first second; TLC: Total lung capacity; DLCO-SB: Diffusion lung capacity for carbon monoxide single breath; GGO: Ground-glass opacity; FEV 1 /FVC: Ratio between forced expiratory volume in the first second and forced vital capacity; HRCT chest: High-resolution CT chest; DPLD: Diffuse parenchymal lung disease; ILD: Interstitial lung disease}

\section{Acknowledgements}

Deep gratitude to all patients accepted to participate in the study.

\begin{abstract}
Authors' contributions
HG put the design of the study and made major contributions to data acquisition and analysis, interpreted the data, and revised it. SE shared with $C T$ interpretation, data interpretation, and extensively revised the work. DS shared in patient recruitment and extensively revised and edited the manuscript. NO helped in data analysis and revised it and was a major contributor in writing the manuscript. All authors have read and approved the final manuscript.
\end{abstract}

\section{Funding}

Not available.

\section{Availability of data and materials}

The data sets used during the current study are available from the corresponding author on reasonable request.

\section{Ethics approval and consent to participate}

The study was approved by the Ethical Committee Board of Ain Shams University and in accordance with the Declaration of Helsinki (FWA: 00017585)

A written informed consent was taken from all enrolled patients; all patient were adults.

\section{Consent for publication}

Not applicable.

\section{Competing interests}

The authors declare that they have no competing interests.

\section{Author details}

${ }^{1}$ Lectureres of Chest Diseases, Chest Department, Ain Shams University, Cairo, Egypt. 'Lecturer of Radiology, Radiology Department, Ain Shams University, Cairo, Egypt. ${ }^{3}$ Associate Professor of Allergy and Immunology, Internal Medicine Department, Ain Shams University, Cairo, Egypt.

Received: 8 July 2020 Accepted: 27 October 2020

Published online: 10 November 2020

\section{References}

1. Putman K, Hatabu H, Araki T, Gudmundsson G, Gao W, Nishino M et al (2016) Association between interstitial lung abnormalities and all-cause mortality. JAMA 315:672-681

2. Wells U, Kokosi A (2016) Subclinical interstitial lung abnormalities: toward the early detection of idiopathic pulmonary fibrosis? Am J Respir Crit Care Med 194:1445-1446

3. Oldham M, Adegunsoye A, Valenzi E, Lee C, Witt L, Chen L et al (2016) Characterisation of patients with interstitial pneumonia with autoimmune features. Eur Respir J 47:1767-1177

4. Sverzellati N, Desai S (2017) Radiology in diffuse parenchymal lung disease and lung nodules. Eur Respir Rev 26(144). https://doi.org/10.1183/16000617. 0049-2017

5. Hansell D, Bankier A, MacMahon H, McLoud C, Müller N, Remy J (2008) Glossary of terms for thoracic imaging. Radiology 246:697-722

6. Riad N, Morshedy N, Shoukri A (2015) Role of pulmonary function tests in screening pulmonary arterial hypertension in scleroderma. Egypt J Bronchol 9:287-292

7. Warrick J, Bhalla M, Schabel S, Silver R (1991) High resolution computed tomography in early scleroderma lung disease. J Rheumatol 18:1520-1528

8. Afeltra A, Zennaro D, Garzia P, Gigante A, Vadacca M, Ruggiero A et al (2006) Prevalence of interstitial lung involvement in patients with connective tissue diseases assessed with high-resolution computed tomography. Scand J Rheumatol 35:388-394

9. Khanna D, Tseng H, Farmani N, Steen V, Furst E, Clements J, Roth D et al (2011) Clinical course of lung physiology in patients with scleroderma and interstitial lung disease: analysis of the Scleroderma Lung Study Placebo Group. Arthritis Rheum 63:3078-3085

10. Watters LC, King TE, Schwarz MI, Waldron JA, Stanford RE, Cherniack RM (1986) A clinical, radiographic, and physiologic scoring system for the longitudinal assessment of patients with idiopathic pulmonary fibrosis. Am Rev Respir Dis 133:97-103

11. Miller M, Hankinson J, Brusasco V, Burgos F, Casaburi R, Coates A et al (2005) Standardization of spirometry American Thoracic Society/European Respiratory Society Task Force. Eur Respir J 26(2):319-338

12. Graham BL, Brusasco V, Burgos F, Brendan GC, Robert J, Adrian K et al (2017) Summary: 2017 ERS/ATS standards for single-breath carbon monoxide uptake in the lung. Eur Respir J 49(1):16

13. Abou Youssuf H, Sabry Y, Abd El-Hafeez A, Mohamed H (2016) Correlation between high-resolution computed tomography of the chest and pulmonary functions in idiopathic pulmonary fibrosis. Egypt J Bronchol 10: 330-336

14. Raghu G, Collard H, Egan J, Martinez F, Behr J, Brown K et al (2011) An official ATS/ERS/JRS/ALAT statement: idiopathic pulmonary fibrosis: evidence-based guidelines for diagnosis and management. Am J Respir Crit Care Med 183(6):788-824

15. Rifaat N, Anwar E, Ali Y, Hassan A (2014) Value of pulmonary rehabilitation in patients with IPF. Egypt J Chest Dis Tuberc 63:1013-1017

16. Hassan C (2018) Comparison of FVC, FVC/DLCO and TIC/DIco as an indicator for interstitial lung disease in patients with scleroderma. Chest 154(4):448

17. Kundu S, Mitra S, Ganguly J, Mukherjee S, Ray S, Mitra R (2014) Spectrum of diffuse parenchymal lung diseases with special reference to idiopathic pulmonary fibrosis and connective tissue disease: an eastern India experience. Lung India 31(4):354-360

18. Kheliouen A, Baough L, Mansouri B, Bendissari K, Zidouni N (2018) Etiological profile of an interstitial lung disease cohort in a Pulmonology Department of Algeria. EC Pulmonol Respir Med 7(7):488-499 
19. Lv H, Liu J, Pan Q, Cai R, Zhang J (2019) Clinical retrospective analysis of interstitial lung disease patients associated with pulmonary hypertension. Med Sci Monit 25:7763-7769

20. Sánchez R, Fernández-Fabrellas E, Samper G, Montañana M, Vilar L (2018) Visual HRCT score to determine severity and prognosis of idiopathic pulmonary fibrosis. Int J Respir Pulm Med 5:84

21. Riad N, Salem H, Diab H (2014) Evaluation of diffusing capacity of the lung for carbon monoxide normalized per liter alveolar volume as a parameter for assessment of interstitial lung diseases. Egypt J Bronchol 8(1):51-56

22. Fessi R, Ourari B, Ben Amar J, Zaibi H, Azzabi S, Baccar M et al (2018) Highresolution computed tomography fibrosis score and pulmonary function tests in interstitial lung disease: is there any correlation? Eur Respir J 52(62):2926

23. Isaac B, Thangakunam B, Cherian R, Christopher D (2015) The correlation of symptoms, pulmonary function tests and exercise testing with highresolution computed tomography in patients with idiopathic interstitial pneumonia in a tertiary care hospital in South India. Lung India 32(6): 584-588

24. Michaelson E, Aguayo M, Roman J (2000) Idiopathic pulmonary fibrosis. A practical approach for diagnosis and management. Chest 118(3):788-794

25. Hunninghake GW, Lynch DA, Galvin JR, Gross BH, Muller N, Schwartz DA et al (2003) Radiologic findings are strongly associated with a pathologic diagnosis of usual interstitial pneumonia. Chest 124(4):1215-1223

26. Sumikawa H, Johkoh T, Colby V, Ichikado K, Suga M, Taniguchi H et al (2008) Computed tomography findings in pathological usual interstitial pneumonia. Am J Respir Crit Care Med 177(4):433-439

27. Mura M, Ferretti A, Ferro O, Zompatori M, Cavalli A, Schiavina M et al (2006) Functional predictors of exertional dyspnea, 6-min walking distance and HRTC fibrosis score in idiopathic pulmonary fibrosis. Respiration 73(4): 495-502

28. Hussein K, Shaaban L, Mohamed E (2016) Correlation of high resolution CT patterns with pulmonary function tests in patients with interstitial lung diseases. Egypt J Chest Dis Tuberc 65(3):681-688

29. Araki T, Nishino M, Gao W, Dupuis J, Putman R, Washko G et al (2015) Pulmonary cysts identified on chest $\mathrm{CT}$ : are they part of aging change or of clinical significance? Thorax 70(12):1156-1162

30. Leonel D, Lucia C, Muñiz A, Hernández M, Blanca M (2012) Pulmonary function test: its correlation with pulmonary high-resolution computed tomography in patients with rheumatoid arthritis. Rheumatol Int 32(7): 2111-2116

31. Hirano C, Ohshimo S, Horimasu Y, Iwamoto H, Fujitaka K, Hamada H et al (2019) Baseline high-resolution CT findings predict acute exacerbation of idiopathic pulmonary fibrosis: German and Japanese Cohort Study. J Clin Med 8(12):2069

32. Lynch D, Godwin J, Safrin S, Starko K, Hormel P, Brown K et al (2005) Idiopathic Pulmonary Fibrosis Study Group: high-resolution computed tomography in idiopathic pulmonary fibrosis: diagnosis and prognosis. Am J Respir Crit Care Med 172(4):488-493

\section{Publisher's Note}

Springer Nature remains neutral with regard to jurisdictional claims in published maps and institutional affiliations.

\section{Submit your manuscript to a SpringerOpen ${ }^{\circ}$ journal and benefit from:}

- Convenient online submission

- Rigorous peer review

- Open access: articles freely available online

- High visibility within the field

- Retaining the copyright to your article

Submit your next manuscript at $\boldsymbol{\nabla}$ springeropen.com 